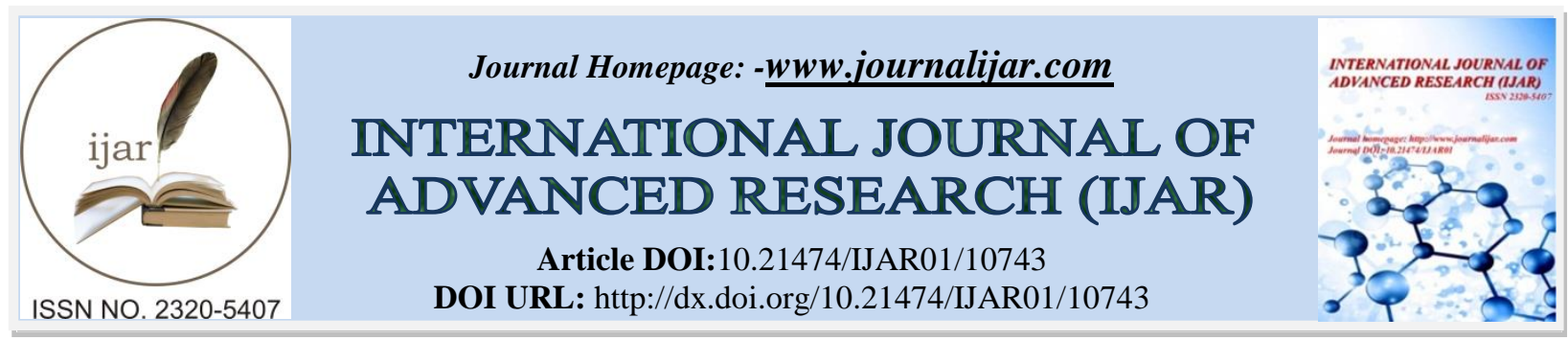

RESEARCH ARTICLE

\title{
ATTITUDE OF THE PEOPLE REGARDING WILDLIFE CONSERVATION, CAUSES OF HUMAN- WILDLIFE CONFLICT AND ITS MITIGATION MEASURES IN KASHMIR VALLEY
}

\author{
Masood Ahmad Dar and Dr. Rayees Afzal Mir \\ Glocal School of Agricultural Sciences Glocal University, Saharanpur, Uttar Pradesh, India-247001.
}

\section{Manuscript Info}

Manuscript History

Received: 05 February 2020

Final Accepted: 07 March 2020

Published: April 2020

Key words: -

HWC, Wildlife, Man-Wildlife Conflict,

Conservation Attitude, Conservation

Psychology

\begin{abstract}
The present study was initiated to assess the attitude of local people living near the forests in ten (10) districts of Kashmir valley during the year 2016 -2018. The main aim was to assess the perception of people regarding wildlife conservation and general knowledge of local populace in this regard. It was also to know about Human-Wildlife conflict and the mitigation measures from the local point of view. About one thousand (1000) people belonging to the age group 18 to 76 years were questioned with hundred (100) from each district making sure each village of the districts belonging to all the five (5) wildlife divisions of Kashmir valley gets covered. population trend, $71 \%$ of the people were of the opinion that the population of the wild animal is increasing while the $19 \%$ of the people responded negative and $10 \%$ of population were not sure and gave no answer. An interesting find during the study was that Leopards and Wolves kill and consume the livestock, but the Black Bears go on silly rampage killing maximum and consuming minimum. About $47 \%$ of the people from all the 10 districts held an opinion that sheep/goat were the cattle depredated most followed by cattle (cow, ox, buffalo etc.) about $31 \%$ by Leopards and Black Bears and horsed around $14 \%$ by Leopards. Only $8 \%$ of the people reported others which included poultry, ducks and pets by Porcupines, Jackals and Foxes.Around 23\% of the people guarding their fields using Dokas (Machans) said that this was by far the most effective method in keeping wild-animals away, $19 \%$ of the people are using watch dogs, $14 \%$ of the people are using the scare crows, $10 \%$ of the people were using wind chimes, around $11 \%$ that of the people were using methods of lighting fire as it is believed that fire has proved to be one of the best deterrent for wild animals.
\end{abstract}

Copy Right, IJAR, 2020, All rights reserved.

\section{Introduction: -}

Human-wildlife conflict refers to interaction between wild animals and people and resultant negative impact on people or their resources, or wild animals or their habitat. Human-Wildlife Conflict (HWC) occurs when wildlife requirements overlap with those of human populations, creating costs both to residents and wild animals (IUCN World Parks Congress). Such a conflict occurs when growing human populations overlap with established wildlife territories, increasing interaction of man and wild animals and thus resulting in increased levels of conflict.

Corresponding Author:- Masood Ahmad Dar

Address:- Glocal School of Agricultural Sciences Glocal University, Saharanpur, Uttar Pradesh, India- 
The assessment of peoples' attitudes and perceptions towards conservation has become an important aspect in many studies of wildlife conservation (Newmark et al., 1993). Wildlife conservation, success depends on the attitudes of people towards conservation (Osmond, 1994; Katrina, 2000). Equally, understanding factors which influence attitudes is important to enable wildlife managers to implement approaches that attract support of stakeholders and the general public. It is necessary to seek and obtain the active participation of potential stakeholders not only in the technical efficiency of aconservation technology, but also the extent of satisfying cultural, social and political considerations in the environment which can help change the attitudes of indigenous people towards wildlife existence and conservation (Newmark et al, 1994; Nji, 2004). People also need to be informed through specific awareness campaigns or environmental education which can help change their attitudes towards conservation.

The current study was aimed to study the attitude of the people regarding wildlife conservation in Kashmir Valley during all the seasons besides understanding the general reason, causes, consequences and mitigation of the conflict in all the ten (10) districts of Kashmir valley during the year 2016 -2018 (Fig. 1). The main aim was to assess the perception of people regarding wildlife conservation and general knowledge of local populace in this regard. It was also to know about Human-Wildlife conflict and the mitigation measures from the local point of view. The State of Jammu and Kashmir is India's northernmost, lying between $32^{\circ} 16^{\prime} 11.28^{\prime \prime} \mathrm{N}$ to $37^{\circ} 6^{\prime} 28.44^{\prime \prime} \mathrm{N}$ and $72^{\circ} 28^{\prime} 10.92^{\prime \prime} \mathrm{E}$ to $80^{\circ} 20^{\prime} 49.92^{\prime \prime} \mathrm{E}$, and sharing international boundaries with Pakistan to the west and China to the north and east. The Kashmir valley is an ancient lake basin, approximately $140 \mathrm{~km}$ long and $32 \mathrm{~km}$ wide with an area of $15925.00 \mathrm{Sq} . \mathrm{Km}$, bound by the Great Himalayan ranges in the north and north-east and by the Pir Panjal range along the northwest and south-east. Elevation ranges from $\sim 1500 \mathrm{~m}$ at the base of the valley to $>6000 \mathrm{~m}$ along the ranges of the Great Himalaya and $\sim 5000 \mathrm{~m}$ along the

Pir Panjal. Kashmir division is one of the three administrative divisions of the Indian state of Jammu and Kashmir. The Kashmir division borders Jammu Division to the south and Ladakh to the east while Line of Control forms its northern and the western border. The Kashmir division consists of 10 districts- Anantnag, Baramulla, Budgam, Bandipore, Ganderbal, Kupwara, Kulgam, Pulwama, Shopian and Srinagar with the total population of 6,907,623.

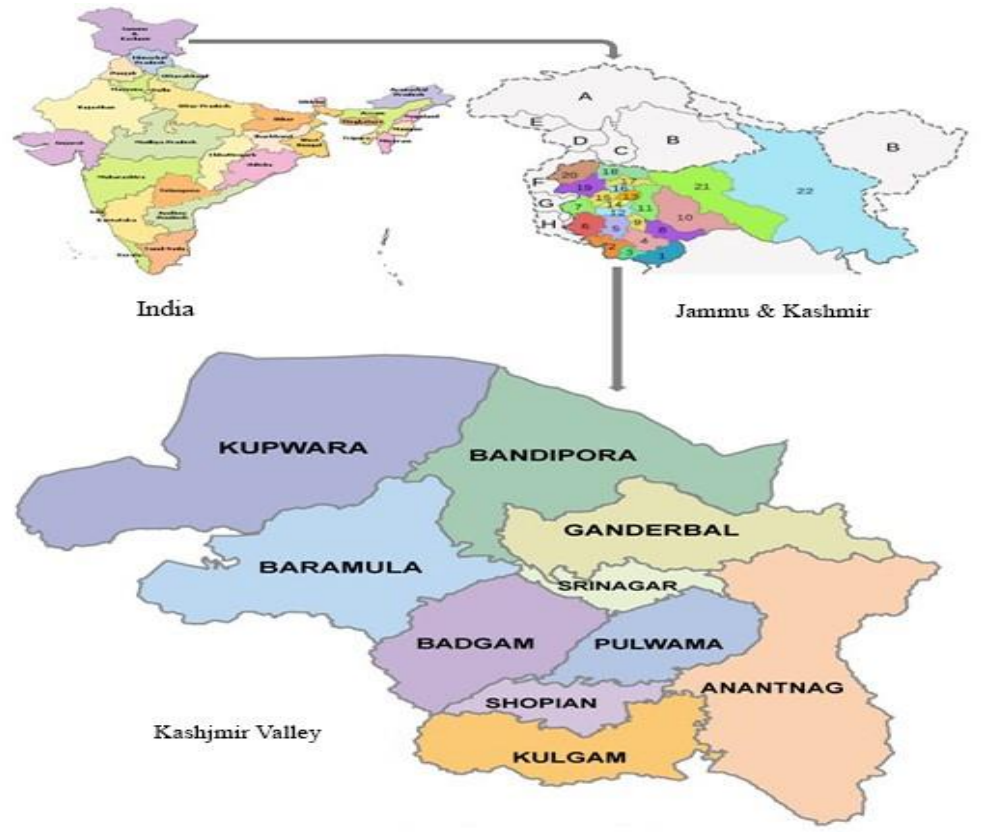

Fig. 1: - District-wise map of study area.

The study was carried out to provide research-based facts to the J\&K Forest/Wildlife Protection department in making policies regarding the conservation and management of wildlife species and their habitat. Each geographic area has a unique pattern of human-wildlife conflict, and it is not similar to other regions. With the above background information, the present study was carried out with the following objective: 
Attitude and perception of the people regarding wildlife conservation, causes of Human-Wildlife conflict and its mitigation measures in Kashmir Valley

\section{Material andMethods: -}

The methodology used to study the Attitude of the people regarding wildlife conservation, causes of HumanWildlife conflict and its mitigation measures in Kashmir Valley was a questionnaire-based survey carried out in all the ten districts of the Kashmir valley. Since this survey based on the questionnaire was the best thing to do this type of study and about one thousand (1000) people belonging to the age group 18 to 76 years were choosen so that all the five (5) wildlife divisions of Kashmir valley gets covered. The 100 individuals per district was chosen from randomly selected villages with a population of $\geq 1000$ individuals. Any participant who could not give complete response due to physical or mental illness were excluded from the study.

Questionnaire based surveys have mostly been used in wildlife science and have always proven beneficial. It is common to assess the nature of the conflict and attitudes of people by using interviews (Kaczensky 2004, Andersone \& Ozolins 2004, Roshaft et al. 2003, Ermala 2003). The standardized questionnaire was prepared in English language and translated to native language and to administer the questionnaire, a face to face interview was conducted in local vernacular language The use of open-ended as well as close-ended type questions in such interviews gives more chance to understand people's ideas, but it also leads to more difficulty when analysing raw data. People were questioned individually to make the results unbiased in order to collect information about the man animal conflict in their areas related to the general opinion about wild animals, their conservation and conflict mitigating techniques. Information was gathered from concerned wildlife officials, print and mass media sources and local people.

First of all, a reconnaissance survey was done on whole study area and then every sampling village was visited for the purpose of collection of data in a well planned manner. Observational/ocular methods were used for this study. Field data was collected fromApril 2016 to May 2018 and was analysed using MS Excel 2016. The details of methods used in this study are given below: -

\section{Primary data:}

In this study, case studies were carried out with special reference to the animal involved, season, time and nature of attacks. Wildlife attacks on humans were identified as predatory or defensive or territorial. The age, sex, nature of damage to humans and animal involved in attack was documented while collecting the field data from the study area. All the cases pertaining to human-wildlife conflict in all the ten districts of Kashmir valley during the study period were studied with the help of special questionnaires, formulated to cover all the aspects of the enquiries regarding damage to humans and their property by wild animals.

\section{Secondary data:}

Past incidences of human-wildlife conflict reported and the details of the ex-gratia claimed were collected from the records of J\&K Forest Department and J\&K Wildlife Protection Department.

\section{Newspaper reports:}

Reports on human-wildlife conflict in the newspapers were collected during the study period and analysed. The referred newspapers were 1. Greater Kashmir, 2. Indian Express, 3. Rising Kashmir 4. Daily Excelsior 5. Daily Aftab 6. Daily Kashmir Uzma.

\section{Results and Discussion: -}

The general perception of the people regarding wildlife, causes of the conflict and measures to mitigate the conflict were sought using a questionnaire. Respondents were from the varied educational and economic backgrounds. They were made well aware about the undergoing study of Human-Wildlife conflict and then the answers were sought from them. Following are the observations/resposces recorded:

Is the population of wild animals increasing?

During the study about 1000 people were questioned, 100 people from each district of the Kashmir valley, when asked about the population trend, $71 \%$ of the people were of the opinion that the population of the wild animal is 
increasing while the $19 \%$ of the people responded negative and $10 \%$ of population were not sure and gave no answer. So majority of the people had a belief that the population of wild animals is increasing (Fig. 2).

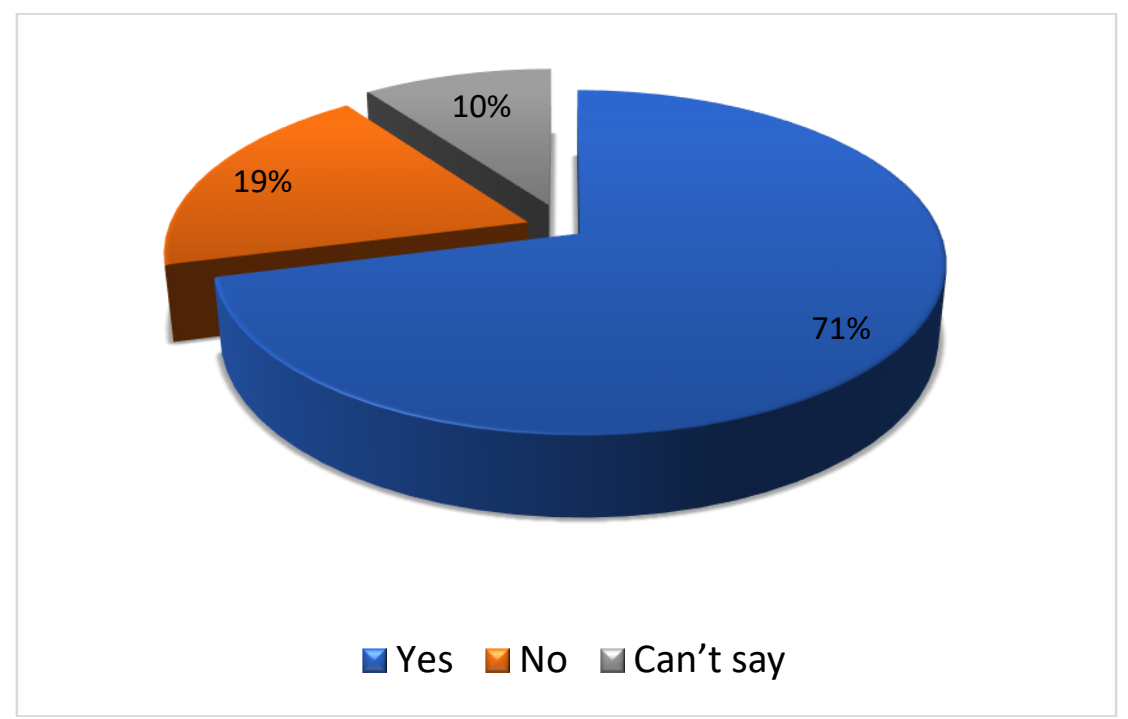

Fig. 2: - Response regarding increase in population of wild animals.

\section{Why do wild animals come down to villages?}

To establish the reasons why these wild animals ventured into the human habitations, different opinions of the people were sorted. Majority of the people (45\%) opined that it was lack of the food that made these wild animals to come in search of the food in the human habitations. The other reason was the plenty of the food available in the human habitations for these wild animals. $28 \%$ of the people advocated that the availability of the plenty food within human habitations drew the wild animals out of the forest. $9 \%$ of the people said it was lack of the water in the forest as some of the animals were found near the water sources in human habitations. $4 \%$ of the people are of the opinion that it is the interspecific as well as interspecific pressure for resources in the forests which lead some animals to enter human habitations. Another $4 \%$ of the respondents did not say anything related to this question (Fig. 3).

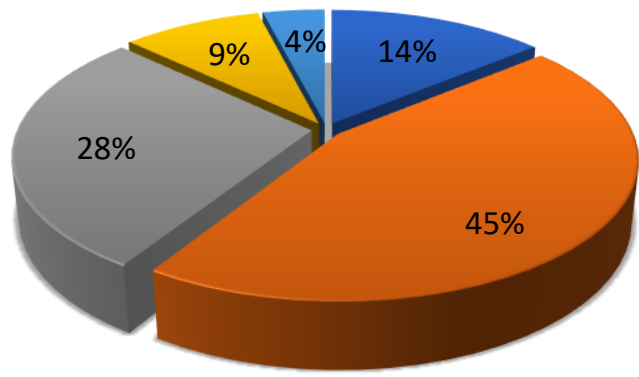

Interspecific \& Intraspecific pressure

$\square$ Lack of food in the forests

$\square$ Plenty of food available in the villages

$\square$ Lack of water

$\square$ No response.

Fig. 3: - Reasons of animals entering to the villages. 


\section{What are the animals frequently visiting the human habitations?}

One of the purposes of this study was to find out which of the wild animals frequently come to the human habitations. The study revealed that majority of the people $(42 \%)$ are of opinion that Black Bears mostly make it to the human habitations followed by the Leopards (35\%), Monkeys (5\%), Wolves (9\%) and others (Porcupine, jackal and Birds) (9\%). So the study clearly indicated that it was Black Bears and Leopards who frequently visit the human habitations. In the northern districts of Kashmir valley, leopards were the main reason of the conflict and in southern districts, it is both Black Bears and Leopard that are responsible and in central districts Black Bear is more involved in conflict but the conflict was low as compared to the north and the south Kashmir (Fig. 4).

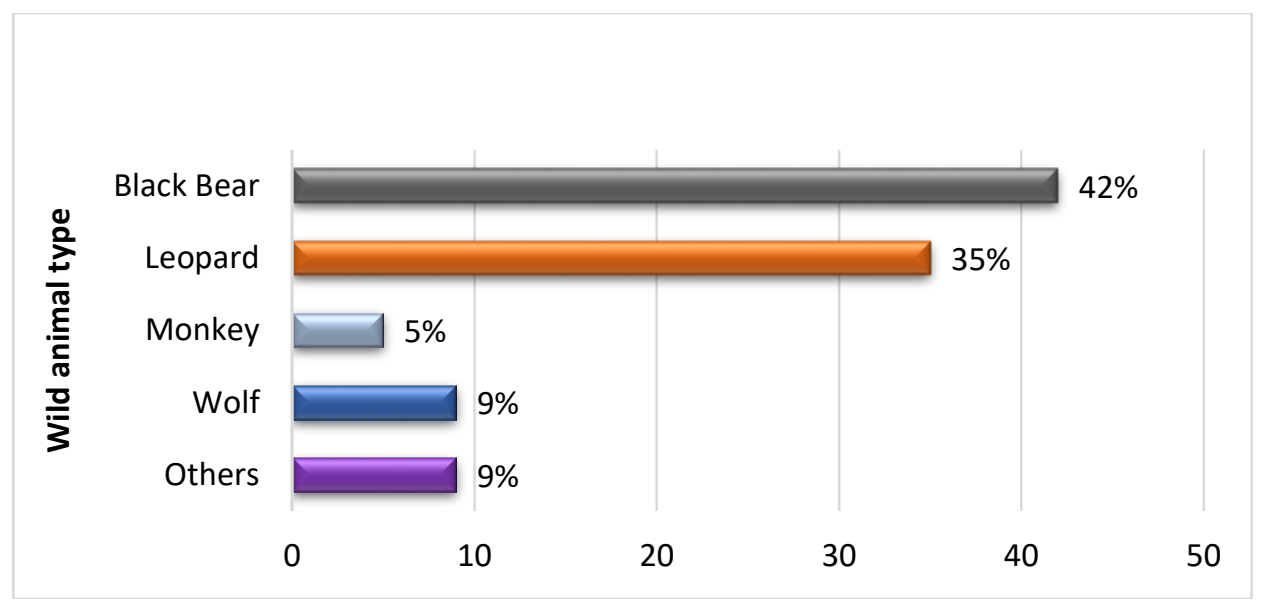

Fig. 4: - Animals frequently visiting the human habitations.

\section{Frequency of visit by wild animals:}

This part of the study was related to the frequency of their visit in the human habitations. The study reveals the number of times the wild animals made it to the human habitations. $18 \%$ of the people said that the wild animals visit their areas daily, while $21 \%$ said the animals visit once a week and $26 \%$ of the people advocated that it was once in the month that the wild animal would come to their areas. But in the majority of the cases $35 \%$ of the people in the area said that the animals could be found anywhere surprisingly in the human habitation (Fig. 5).

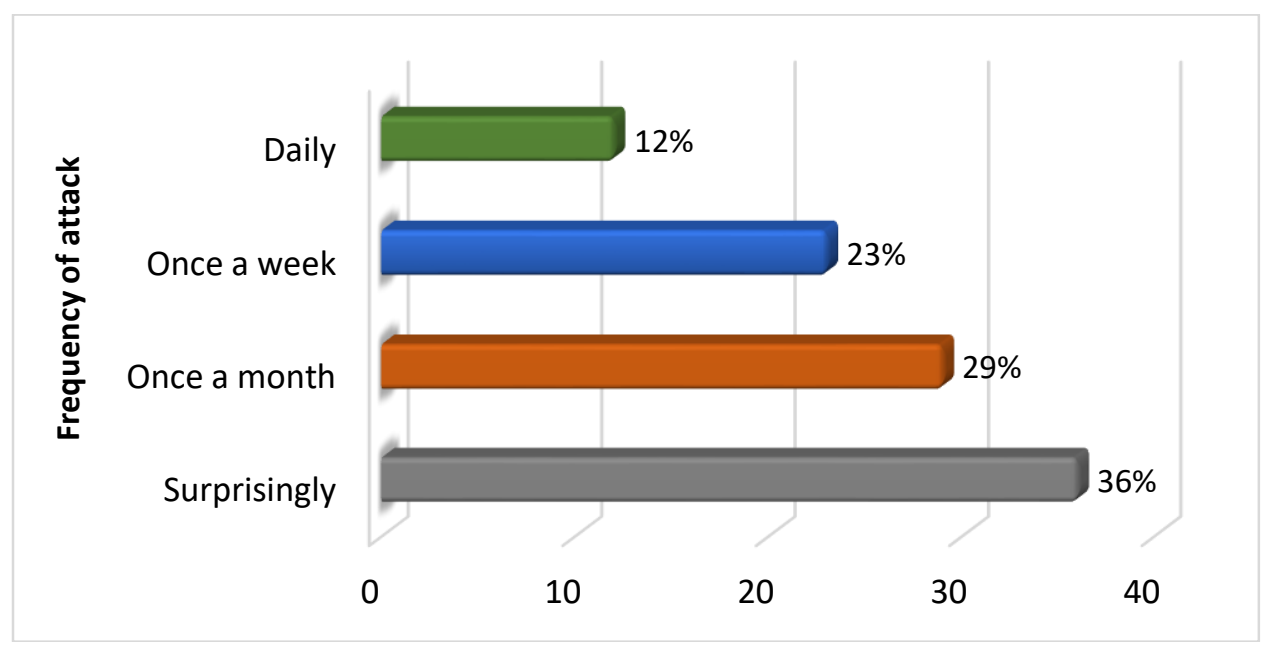

Fig. 5: - Frequency of animal visits.

\section{What is the type of animal visiting in the area?}

When the people of the conflict affected areas were asked about the nature of raids by wild animals in their areas, the $63 \%$ of these people said that animals come solitary (alone). About $27 \%$ of the people said that the wild animals come in the family (Mother with their cubs) and $10 \%$ of the people said that the wild animals visit the human habitation in a group. So the general perception that the people adhere to is that mostly these wild-animals roam 
around singly, which has been observed in most of the cases whenever any wild animal comes into the human habitations (Fig. 6).

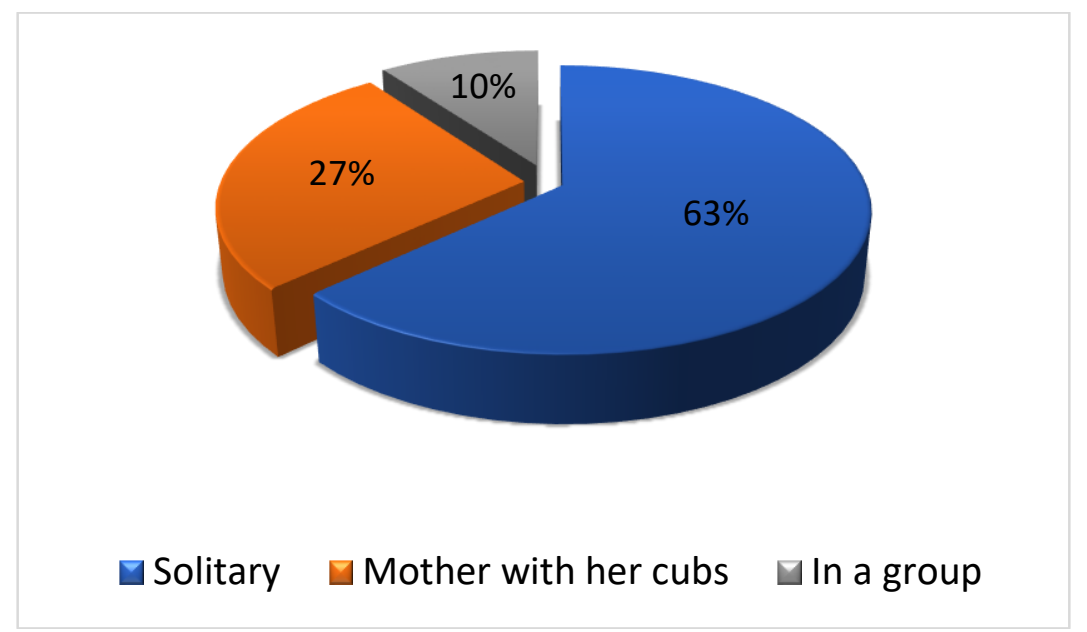

Fig. 6: - Type of visiting animals visiting the villages.

\section{Kind of the livestock depredated and the animals involved?}

When it comes to estimating losses inflicted by wild animals in terms of livestock damage, goats/sheep are the animals depredated most and the animals involved may be Leopards, Black Bears or Wolves. An interesting find during the study was that Leopards and Wolves kill and consume the livestock, but the Black Bears go on silly rampage killing maximum and consuming minimum. About $47 \%$ of the people from all the 10 districts held an opinion that sheep/goat were the cattle depredated most followed by cattle (cow, ox, buffalo etc.) about $31 \%$ by Leopards and Black Bears and horsed around $14 \%$ by Leopards. Only $8 \%$ of the people reported others which included poultry, ducks and pets by Porcupines, Jackals and Foxes. It is pertinent to mention here that sheep/Goats being less in body mass are easy to be overpowered by the predators, hence been highly killed (Fig. 7).

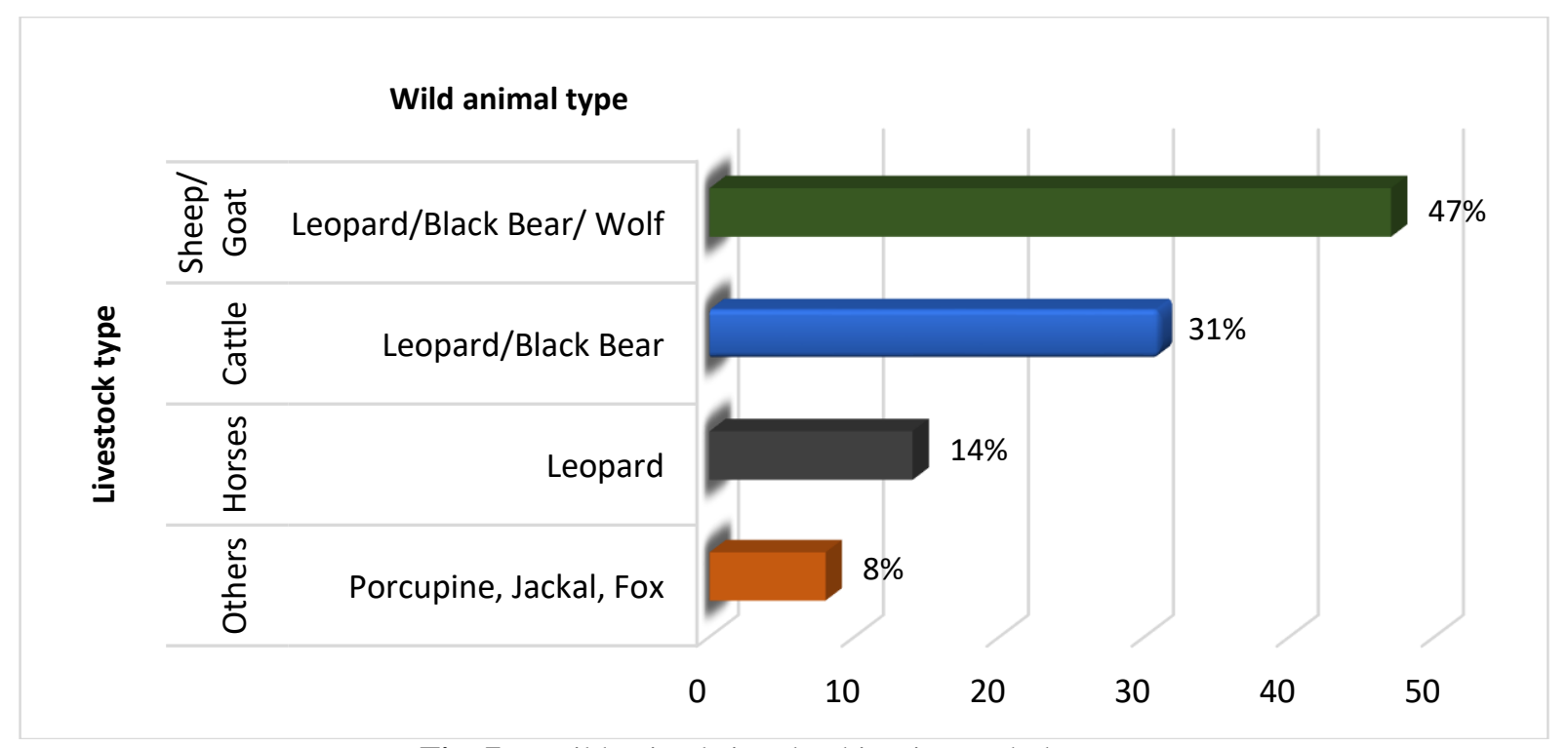

Fig. 7: - Wild animals involved in Livestock damage.

\section{Crop damaged and the Animal involved:}

For estimating the crop damage and the animals involved it was observed that Black Bears, Monkeys and Porcupines cause much damage by destroying crops like maize, apples, cherry, walnut, almonds, saffron, vegetables and other plants. The $36 \%$ of the respondents said that maize was the most damaged crop by Black Bears and Monkeys, and about $40 \%$ of the crop was damaged by these animals living close to the forests. Next $32 \%$ people 
said that in case of damage to apples, the animals involved was mostly the Black Bear. The study revealed that Black Bears not only destroy the fruits but damage the trees also which increases the magnitude of the damage. The $18 \%$ respondents suggested about damage to cherry by Black Bears while it was $14 \%$ and $4 \%$ regarding Walnut by Black Bear and others by Porcupine respectively (Fig. 8).

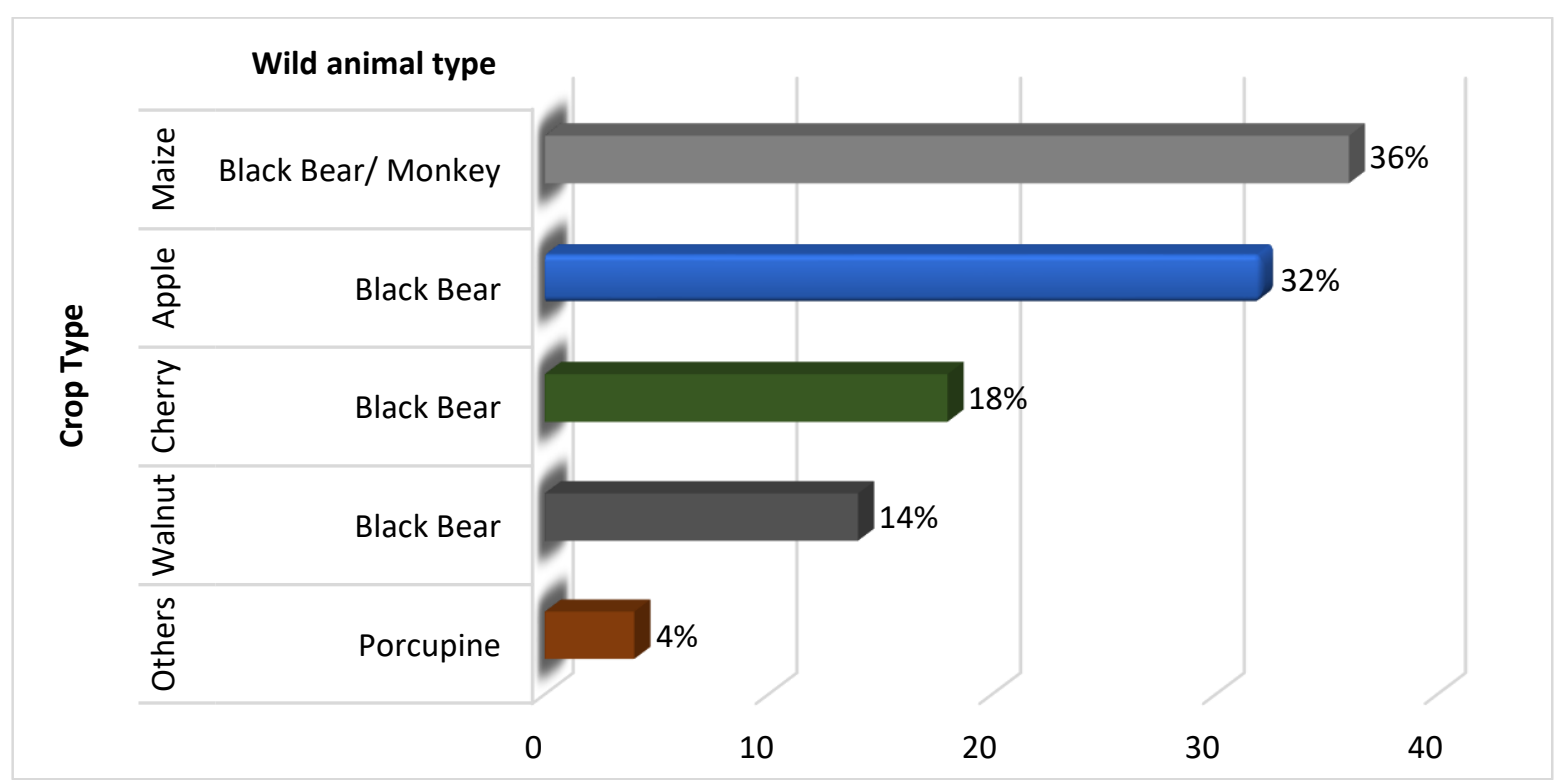

Fig. 8: - Crop damaged and the Animal involved.

\section{Can the attacks by wild animals be prevented?}

When the people were asked about their opinion regarding prevention of animal attacks, they were of the different thoughts. Around $60 \%$ of the respondents said that the attack by the wild animals can be prevented and around $32 \%$ of people advocated that the attacks by wild animals can't be prevented and $6 \%$ were not sure of any reply about this question. Most of the people were optimistic enough to say yes that these attacks can be prevented and any of the methods employed by the people themselves without the aid of the Government can help in keeping wild animals away from entering human habitations. As per these respondents, Government does nothing except paying a meagre amount of compensation only when a person loses the life or gets injured. No compensation is paid by the Government for the crop damage or livestock damage (Fig. 9).

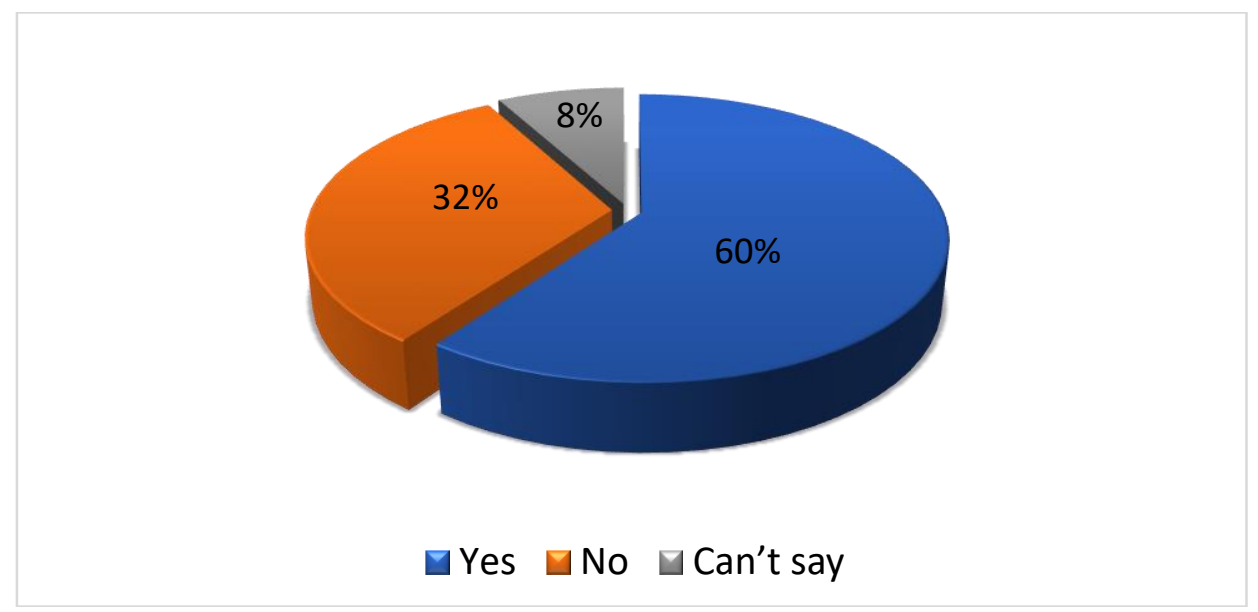

Fig. 9: - Response regarding prevention of animal attacks.

Methods/deterrents to keeping wild animals away and their effectiveness?

The study has showed that the wild animals can be kept away from the human habitations by the following methods, their effectiveness also got revealed during the study because people used any of these methods to less or more 
extent. Around $23 \%$ of the people guarding their fields using Dokas (Machans) said that this was by far the most effective method in keeping wild-animals away, $19 \%$ of the people are using watch dogs, $14 \%$ of the people are using the scare crows, $10 \%$ of the people were using wind chimes, around $11 \%$ that of the people were using methods of lighting fire as it is believed that fire has proved to be one of the best deterrent for wild animals. Nearly $7 \%$ of the people suggested to using the method of burning the rubber tyres, and $9 \%$ use crackers and do the drum beating hardly, $3 \%$ of the people are using cow dung deposits and $4 \%$ said that they use different methods to keep wild animals away (Fig. 10).

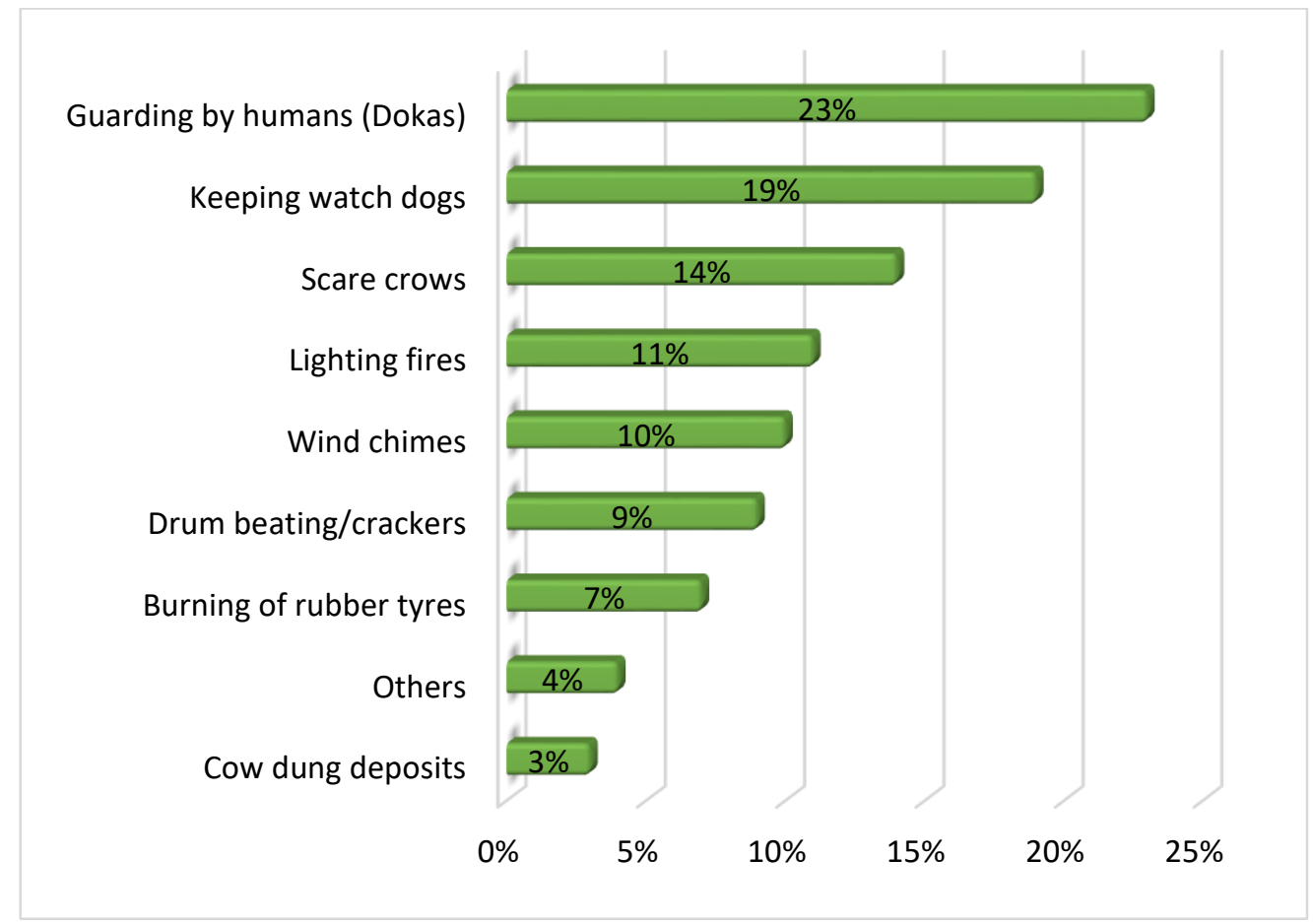

Fig. 10:- Effectiveness of different methods to keep animals away.

\section{Conclusion: -}

In the first place, the greatest enemy to wildlife conservation isignorance as to conservation and management of naturalresources. In this regard, the cooperation of all stakeholders (for example, community, government, conservationists and other conservational funding bodies) is crucial for lasting success in wildlife and environmental conservation. This initiative will require the adoption of conservation strategies, lawsand policies that are proactive, mutually beneficial and environmentally friendly and sustainable. Secondly, negative attitudes and perceptions can be shifted with carefully implemented conservation programs which serve to alleviation poverty by initiating entrepreneurial activities that can generate income/employement to the local residents to offset the costs incurred. At the same these initiatives serve to discourage land-use strategies that are incompatible with wildlife conservation.

\section{Recommendations: -}

Some measures which can be taken in tackling Human-Wildlife conflicts are as under:

1. Habitat Restoration practices

2. Declaration of new protected areas

3. Organizing awareness programs

4. Employment to the locals in forest/wildlife department and projects

5. People must avoid disturbing or irritating wild animals

6. Compensation schemes by Government

7. Advanced Infrastructure and training

8. Proper Law enforcement

9. Avoid horticulture plantations near forests and Protected Areas

10. Precautions must be taken when away from home 


\section{References: -}

1. Andersone Z. \& Ozolins, J. (2004) Public perception of large carnivores in Latvia. Ursus, 15, 181-197.

2. Athreya V., Odden M., Linnell J. D. C. and Karanth K. U. (2011). Translocation as a tool for mitigating conflict with leopards in human-dominated landscapes of India. Conservation Biology, 25(1):133-141.

3. Charoo S. A., Sharma L. K. \& Sathyakumar S. (2011). Asiatic black bear-human interactions around Dachigam National Park, Kashmir, India. Ursus 22(2):106-113.

4. Chauhan A. and Pirta R. S. (2010b). Public opinion regarding human-monkey conflict in Shimla, Himachal Pradesh. J. Human Ecology, 30(2): 105-109.

5. Conover M. R. (2001). Resolving human-wildlife conflicts: the science of wildlife damage management. CRC press.

6. Dar M. A. (2007). Ecology of Leopard and Himalayan Black Bear in and around Dachigam National Park, with special reference to Human-Wildlife Conflict. M. Sc. Wildlife Science Dissertation. Dept. of Wildlife Science, Aligarh Muslim University (AMU), Aligarh U.P.

7. Dar M. A., Sathyakumar S.\& Koul R. (2012). Himachal Pradesh Bear Conservation and Welfare Action plan. Wildlife Trust of India.

8. Dar M. A \& Mir R. A. (2019). Causalities of Human Wildlife Conflict in Kashmir valley, with special reference to Leopard and Asiatic Black Bear. IJRAR, 6 (1): 701-706.

9. Dickman AJ (2010) Complexities of conflict: the importance of considering social factors for effectively resolving human-wildlife conflicts. Animal Conservation 13: 458-466.

10. Ermala A. (2003) A survey of large predators in Finland during the 19 th $-20^{\text {th }}$ centuries. ActaZoologicaLituanica 13: $15-20$.

11. Graham K, Beckerman A. P. Thirgood S. Human-predator-prey conflicts: ecological correlates, prey losses and patterns of management. Biological Conservation. 2005; 122: 159-171.

12. Kaczensky, P., Blazic, M. \& Gossow, H. (2004) Public attitudes towards brown bears (Ursusarctos) in Slovenia. Biological Conservation, 118, 661-674.

13. Lamarque F, Anderson J, Fergusson R, Lagrange M, OseiOwusu Y, Bakker L (2009). Human-wildlife conflict in Africa: cause, consequences and management strategies. Conserv. Biol. 17:1512-1520.

14. Madden F. Preventing and mitigating human-wildlife conflicts: World Parks Congress recommendation. Human Dimension Wildl. 2004; 9:259-60.

15. Newmark WD, Manyanza DN, Gamassa Deo-gratias M (1994). The conflict wildlife and local people living adjacent to protected areas in Tanzania: human density as a predictor: Conserv. Biol., 8: 249-255.

16. Newmark WD, Manyanza DN, Gamassa Deo-gratias M (1994). The conflict wildlife and local people living adjacent to protected areas in Tanzania: human density as a predictor: Conserv. Biol., 8: 249-255.

17. Nji A (2004). Why poor people remain poor. Key elements for poverty reduction and sustainable development. Yaoundé, Cameroon Buma Kor Publishers. Pp. 240.

18. Osmond P (1994). Wildlife-Human conflicts in Kenya: Integrating wildlife conservation with human needs in Masai Mara region; PhD Thesis, McGill University, Montreal.

19. Røskaft, E., Bjerke, T., Kaltenborn, B.P. \&Linnell, J.D.C. (2003) Patterns of self-reported fear towards large carnivores among the Norwegian public. Evolution and Human Behaviour, 24, 184-198. 